\title{
Third-Party Application Maintenance Management
}

\author{
Samia Naciri \\ ENSIAS, Mohamed V University -Souissi \\ BP. 713, Agdal, Rabat, Morocco
}

\author{
M. A. Janati Idrissi \\ ENSIAS, Mohamed V University -Souissi \\ BP. 713, Agdal, Rabat, Morocco
}

\begin{abstract}
The success and failure of software projects are based on performance indicators such as: compliance to the customer first requirements, customer satisfaction, software quality, budget overrun, schedule compliance and so on.

Certainly, project management approaches and best practices known in the field of software engineering or others have been used in software maintenance (SM) management to better position these performance indicators and therefore promote project success.

This paper concerns especially Third-party Application Maintenance (TPM). It presents and discusses the few approaches proposed in the literature that have been able to meet the challenges of this software engineering area under specific conditions and in an outsourcing context.
\end{abstract}

\section{General Terms:}

Software maintenance, TPM

\section{Keywords:}

Software maintenance outsourcing, Software maintenance management, Third-Party Application Maintenance, TPM

\section{INTRODUCTION}

The change over investment economy to breakdown economy has brought to light new economic concepts such as outsourcing. The concept of outsourcing means the subcontracting of the non-strategic activities like support activities. The outsourcing comes to replace the technical assistance economic model with governed resources.

The Information Technology (IT) outsourcing is one of the first kind of business subcontracting.

In this new economic model, software maintenance is one of the most concerned areas. Third-party Application Maintenance (TPM), managed services and outsourcing, all are similar terms related to the outsourcing of software maintenance activities.

Wikipedia defines TPM as the maintenance of software, provided by an external expert in the field of information technology and communication. This TPM definition is based on two concepts: software maintenance and external expertise or outsourcing.

In order to understand the issues and the specificities of this software engineering area, this paper is organized in 4 sections.

The first section presents the software maintenance definitions, categories and process. It is followed by an overview of the Thirdparty Application Maintenance (TPM) field including definition and context.

The third section discusses the management concepts and how it can be approached for TPM field. It will help us furthermore to identify issues and challenges of TPM management methodologies.

Before concluding, we present some TPM literature topics to have more knowledge concerning recognized research areas and problematic identified by SM researchers and practitioners.

\section{SOFTWARE MAINTENANCE}

Software maintenance (SM) is defined by the Standard of software Maintenance, IEEE 1219 as "the modification of a software after its delivery, which the goal is to correct anomalies, to improve performance or to rehabilitate the product with the environment changes". This definition presents SM as corrective and perfective activities Also, The standard ISO 12207 (standard for software life cycle process) regards the software maintenance as a primary process of the life cycle of a software and defines it as being "the modifications of a software (its code) and of its documentation caused by a problem or a need to improve it". The standard ISO 14764, suitable for maintenance, takes the same definition.

The first two definitions do not clearly state the evolving nature of software maintenance activities contrast to the [15] definition. The Software Maintenance in [15] means the evolution of the software. In general, it is described by the experts as being all required activities that can provide an effective support to a software system. These activities are carried out as well during the stages before the delivery as after the delivery [4].

Software maintenance or maintenance of the software can be summarized as all activities of support and engineering of software changes (code, documentation, ....) in order to meet the user's needs. These changes can evolve software existing features as they can be only anomaly corrections.

\section{1 classification of the Software Maintenance}

The software maintenance is essential as far as it allows ensuring a continuous use of the software and integration of customer 
requirements not implemented during the software development phase.

The standard ISO 14764 proposes an international classification standardized according to two dimensions:

-Dimension : time or moment of the modification. It includes two types of software maintenance, proactive maintenance and reactivate maintenance,

-Dimension "goal" of the modification. It includes corrective maintenance and enhancements.

Research show that almost $80 \%$ of the maintenance activity (figure 1), is dedicated to software enhancements (perfective maintenance, preventive maintenance and adaptive maintenance), this is the primary reason why certain researchers rename the software maintenance by " software evolution".

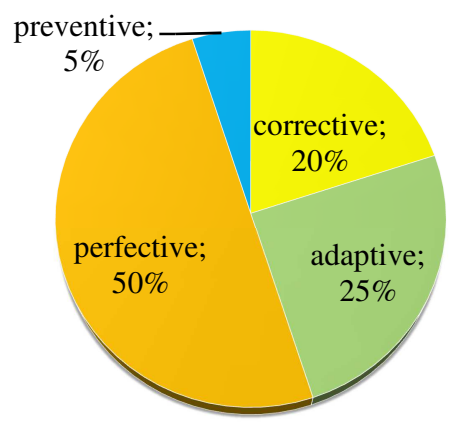

Fig. 1. distribution of SM classes [4]

The customer support is a category of SM that doesn't require programming activities. It is an important area of effective communication, which helps maintainers to clarify change requests submitted by customers. The support activity involves giving the needed support to the software product end-users, to qualify detected bugs, to ensure about their relevance and also to train end-users on product features.

\subsection{Software maintenance process}

Before introducing the main SM process, it's important to note that software maintenance process describe how to organize maintenance activities [11]. It is similar to the software development process, however the focus is on software product correction and adaptation, not just on the transformation of requirements to software functionalities

International standard ISO/IEC 14764 defines the life cycle of the SM in six processes(figure 2). The SM begins at the time from putting the software to production. This is the process of "establishment", then SM enters a continuous loop formed by three processes " problem and modification analysis", "modification implementation" and "review and acceptance". The maintenance process which does not happen every day is the" retirement" partial or final of the software.

The software maintenance process can be influenced by several environmental factors identified in [11], such as:

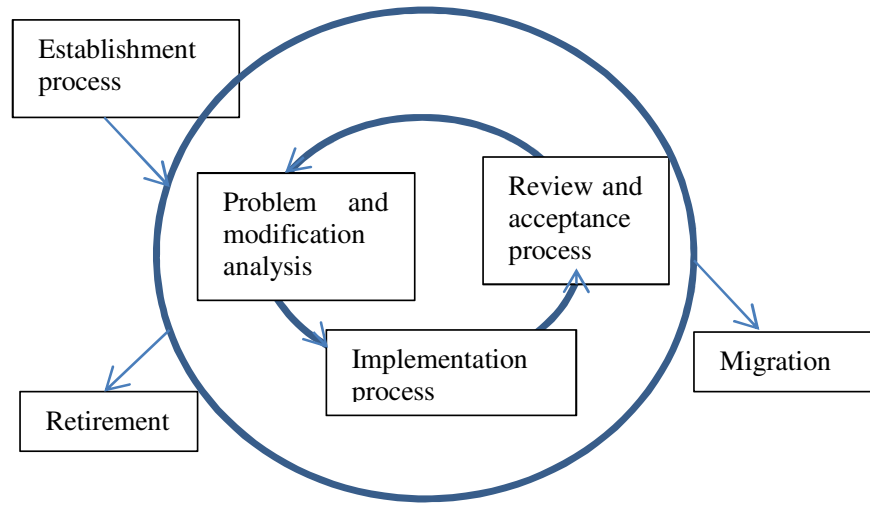

Fig. 2. SM meta-process (ISO/IEC 14764)

-Maintenance activity type: like corrections, new requirements, enhancement for existing requirements or change of the implementation mode,

-People: it concern's persons skills and aptitudes, also if they are customers or users,

-Product: its size, age, type and product technical architecture,

- Process organization: it is concerning the management approach used, team organization, methods, resources and technologies.

this paper takes the same viewpoint for the identified factors in [11], but we propose to consider the urgent (non-plannable) software maintenance among first factors. Software maintenance process may be affected and influenced if it didn't take into consideration what can generate this kind of software maintenance. Especially, since it affects the customer satisfaction management.

\section{THIRD PARTY APPLICATION MAINTENANCE (TPM)}

Broadly speaking, we consider the engineering of the TPM is the whole maintenance activities carried out by a third party, whic relate to software, allowing:

- To correct anomalies, to optimize and improve the product reliability, to develop new functionalities or to evolve the existing functionalities.

- To ensure the performance of the software,

-To improve product quality, the development process and the upgrade of the development tools and the infrastructure...,

- To bring a functional and technical support for the customer project manager and also for the customer exploitation teams,

As well as other types of activity taking care to keep the software in an operational state. These activities are monitored and controlled by Service Level Agreement (SLA) indicators in accordance with the contract drawn up between the customer and the SM provider (maintainer). SLA is defined in [11] as an agreement between the providers of a maintenance service and the customers that specifies the performance targets for the maintenance service.

The nature of the maintenance activities requires, according to [11], a permanent contact with customer, short cycles and iterations and reduced deadlines for the replies. 


\subsection{Outsourcing}

The purpose for companies to decide outsourcing SM projects is strategic. Each company aims to achieve organization goals, often, to focus themselves on the core trade of the company and to be detached from support activities (todo add reference). On the other hand, software maintenance providers have enough experiences and advanced skills which can help to manage efficiently this type of project .

The outsourcing community must be fitted with tools and sophisticated methods of project management and quality control with a high level of reusability. It requires also qualified personnel. In this field, an industrialization of the software maintenance process is capital.

The software outsourcing can be of various forms: onshore, near shore, or offshore....

\subsection{TPM topics exploration}

Through an exploration of TPM literature topics, we have inventoried several research areas (cf. table 1) related to this maintenance field. This section aims to present the result of our research using multiple keywords related to TPM. this section present two categories of topics. The first category treats the initialization phase of TPM project (like outsourcing decision). The second category deals the post-project topics that can be covered by "TPM management area".

Table 1. TPM research areas findings

\begin{tabular}{|c|c|}
\hline $\begin{array}{l}\text { Customer related } \\
\text { topics (TPM } \\
\text { initialization } \\
\text { phase) }\end{array}$ & $\begin{array}{l}\text {-Outsourcing decision } \\
\text {-Providers Selection factors } \\
\text { —SM offshore problems and challenges }\end{array}$ \\
\hline $\begin{array}{l}\text { Maintainer } \\
\text { related topics }\end{array}$ & $\begin{array}{l}\text {-Productivity and performance of } \\
\text { outsourcing product and metrics } \\
\text { —Customer satisfaction and quality } \\
\text {-Planning and predicting SM } \\
\text {-Risk management of outsourced } \\
\text { projects } \\
\text {-Project management strategies }\end{array}$ \\
\hline Common topics & $\begin{array}{l}\text { - Governance in outsourcing } \\
\text {-IT outsourcing contract and the } \\
\text { customer-supplier relationship, } \\
\text { - Conflict between customer and } \\
\text { providers } \\
\text { - First signs of SM failure } \\
\text { - Typology, classification, process } \\
\text { - Success factors of offshore projects } \\
\text { - Cultural, coordination, communication } \\
\text { and relational aspects }\end{array}$ \\
\hline
\end{tabular}

A number of TPM research areas are briefly presented in the following paragraphs.

3.2.1 Outsourcing decision. The paper [7] discuss that the outsourcing decision of company's activities is founded on activities position according to two dimensions:
- The dimension: strategic / non-strategic. It considers how important the activity to be outsourced to the organization in achieving strategic goals,

- The dimension: competitive / non-competitive. It considers how the activity, to be outsourced, is currently performed compared to the external competitive marketplace.

The outsourcing decision is not necessarily related to cost reduction. Outsourcing allows having a high level of quality and professional service.

3.2.2 Success factors of offshore projects. According to Gartner group forecasts(todo add ref), the market of IT outsourcing has evolved from 2003 to 2010 at a rate of $7.2 \%$ of annual revenue.

Despite this progress, IT outsourcing lives through several problems. Statistics show that more than $50 \%$ of IT outsourcing contracts are finished early.

The success of outsourced projects depends on several factors such as:

-Optimal outsourcing contract negotiation,

-Outsourcing contract management

-Building and maintaining a good customer-service provider relationship.

3.2.3 Risk management of the outsourcing projects . The outsourcing project risks are various: project size, misinterpreted requirements, unavailability of qualified personnel, the customer experience in outsourcing, etc.

As part of an outsourcing commitment formalized by a contract, and from a provider perspective, the study [3] has identified three categories of risks and mitigation strategies related to TPM:

-Risks specific to the project,

-Macroeconomic risks,

-Risks specific to the customer-supplier relationship.

3.2.4 The conflict between customer and supplier. Among the root causes of disagreement between the customer and the supplier, the paper [10] cites:

-Ambiguity and misunderstanding of the contract itself. The main root causes of contractual litigation between the customer and the provider is the requirements changes after scope validation.

- The historical failure of the software industry in the quantification of the real dimension of the project before starting it.

3.2.5 Cultural, relational, coordination, and communication aspects. In a wider context than the TPM, the paper [6] references two categories of distance to be considered between the customer and the outsourcing provider, the outside distance and the inside distance.

-Outside distance: related to the geographic, cultural and temporal differences,

-Inside distance: concerns differences related to organizational, technological and knowledge.

Those distances impact imperatively the communication, coordination, culture and the monitoring of the TPM project. 
3.2.6 Productivity and performance of outsourcing projects. Oftentimes, the TPM customer does not have a complete view of the work carried out by the maintainer, since, sometimes; the TPM does not impact the user experience on the software. To improve customer perception of the SM, it is important to provide a better overview of the activities undertaken by the service provider of $\mathrm{SM}$ and document such work with neutral measures.

The research paper [2] measures and analyzes the productivity of a telecom project using SM standard common measures: size, level of effort, quality and schedule. This work can only be done, whether each SM process (definition activities process, monitoring application process and recording of SM team time process) is well implemented and respected.

\section{TPM MANAGEMENT FINDING}

The TPM is positioned inside a complex and competitive environment. It is faced several challenges on various levels: management, human resources, business, security. It is under a continuous pressure of cost reduction. Without an effective management methodology, TPM cannot achieve their contractual commitments with the customer. The concept of management indicates the act or art to exert the executive, administrative and control direction as explained in [9].

Largely speaking, [5] notes that management is "the process of design and maintenance of an environment in which the individuals work together in groups to effectively achieve the selected objectives". Management is composed to five distinct functions: planning, organizing, staffing, directing and controlling.

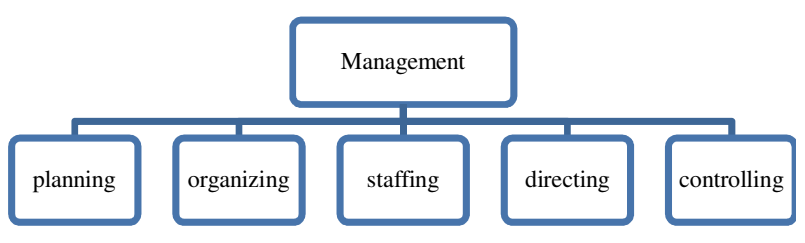

Fig. 3. management functions in

This is a generic definition which organizes management in five functions; each function has a large scope of activities and process that we can define to achieve project goals.

In the same way, the standard IN 13306:2001 defines the maintenance management as being "All the activities of the direction instances which determine the goals, the strategy and the responsibilities as regards maintenance and which applies them by means such as planning, control of maintenance, improvement of maintenance activities and the economic aspects." referring to [12].

Similar to an iceberg, according to several articles and surveys (EDP Analyzer in 1972), software maintenance is often under estimated, carrying risks and generating hidden costs. This phase of the SM project consumes a large number of organization resources, estimated at more than 3/4 of the investments which are made after the delivery of the software (a cost between $50 \%$ and $80 \%$ of the budget of the DSI).

\subsection{TPM management problems}

Although an analysis of several papers and taking into account our experience on TPM industry, we can confirm that TPM manage- ment is different than development project management. Firstly, the TPM management is confronted with the characteristics requiring particular techniques of management sciences [1], such as:

- The change requests arrive in a random way preventing a strict annual planning,

- The requests are studied and classified by a set of priorities,

- The size and the complexity of the requests requires the intervention of only one or two persons,

- The main aim of the maintenance team is the daily performance of the software in production (maintain the product in Operational Condition)

-The priorities can change (for example: correction of "blocking" bugs will pass before any other modification).

- The stakeholder support management, customer management, end user management, maintenance team management and others.

Additionally to previous characteristics, for TPM management, it's added specificity of outsourcing management which must be considered, specifically:

- The respect of the contractual commitments (SLA, quality...);

- The trust degree between customer and service provider or maintainer;

- The bandwidth allocated to the communication and the used channels type:

- The lack of visibility on the business and technical context

- The long time to have a feedback because of the distance and of a time zone difference;

- The management of complex configuration;

- The focus on the people and the cultural difference;

- The change request management and the ability to understand requirements;

By what precedes, we summarize on the diagram below the main features of TPM management ontology. The diagram illustrates three parts(figure 4 )

-A first part requiring to control the techniques of project management

-A second part concerning the management of priorities and the production

—And a last part is specific to the outsourcing management.

The TPM management must be based on a flexible and modern approach based on reliable best practices of management and making it possible to achieve managerial goals of software maintenance and outsourcing.

\subsection{TPM Management approaches}

There are several standards, tools and best practices referential helping to better managing the TPM. However, there is not a universal method which goes whatever the project characteristics. Excellence in management is often judged on the continuity of the project's success. Without being based on a reliable management methodology, the projects success repetitiveness cannot be guaranteed.

In order to help the TPM manager with the choice of which approach use for TPM management, we have explored the three main project management methodologies.

A methodology is defined as a set of forms, models, guidelines 


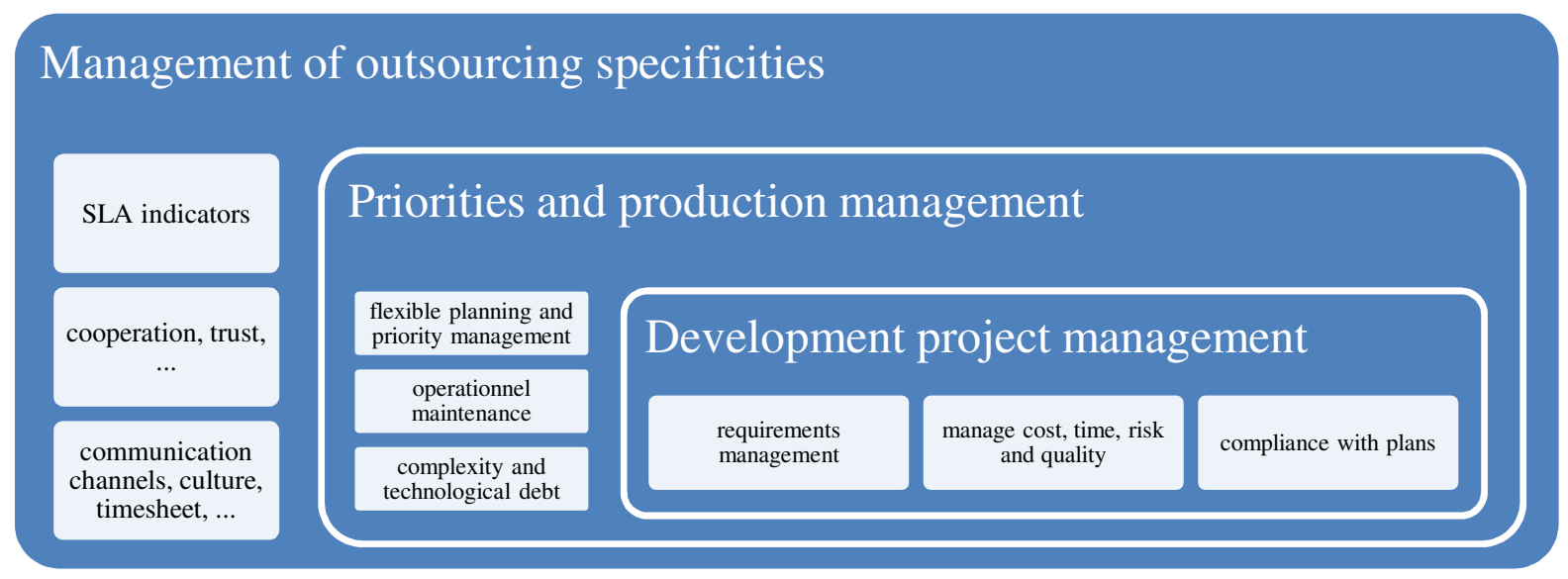

Fig. 4. TPM management proposed ontology

and checklists which we apply to a project or a specific situation. Certainly, having only one management methodology applicable independently of the project environment or context does not ensure a success of all projects. A methodology needs to be adapted to meet customer needs and project environment changes. The choice of which methodology to adopt is not evident. It depends on several factors such as: strategy of the organization, project size, its priority, its severity and so on management approaches in the literature are presented in three categories: traditional management approach, management approaches based process and management approach based on human interaction. the paper provides below an introduction of each approach type with examples.

Traditional management approach: characterized by a sequence of successive stages. Traditional management methodologies of project; also named waterfall; date back to 1950. It is an approach seen by [13] as "predictive", driven by a planning that resists to change. It is characterized by:

-A tunnel effect: lack of visibility of the product until the delivery, with a tardy emergence of the risk factors,

- It sometimes leads to a poor communication,

-A production of large documentation (theory) which delays the realization.

the table (cf. Table 2) presents a comparison between the three main standards known in the management approaches process based based on paper [8] study

-Capability Maturity Model Integration (CMMI): a repository of best practices and a management system to assess the maturity of the organization,

- Software Maintenance Maturity Model (S3m): a development model based on CMMI, ISO9001: 2000, the Camellia pattern, CM3, SITOUNI model, COBIT. S3m is designed specifically to manage SM processes,

—And Information Technology Infrastructure Library (ITIL): a repository of best practices for service management which is included in the concept of IT operations.

Through the above table, we conclude that the three management standards cannot cover TPM management needs for normal or
Table 2. Comparison of main management standards of TPM

\begin{tabular}{|c|c|c|}
\hline CMMI & S3m & ITIL \\
\hline $\begin{array}{l}\text { Advantages: } \\
\text {-For the software de- } \\
\text { velopment project } \\
\text { limited in time } \\
\text { with a defined goal } \\
\text { as opposed to the } \\
\text { continuous nature } \\
\text { of the maintenance } \\
\text { activity. }\end{array}$ & $\begin{array}{l}\text { Advantages: } \\
\text {-Applicable to } \\
\text { software mainte- } \\
\text { nance process, it } \\
\text { is a mapping (a } \\
\text { transposition) of } \\
\text { Maturity Model } \\
\text { - CMMi is enriched } \\
\text { processes and } \\
\text { practices directly } \\
\text { inspired from soft- } \\
\text { ware maintenance } \\
\text { models and infor- } \\
\text { mation technology } \\
\text { models, }\end{array}$ & $\begin{array}{l}\text { Advantages: } \\
\text {-Manages opera- } \\
\text { tions to leave the } \\
\text { production in an } \\
\text { operational state, } \\
\text {-Focuses on servers, } \\
\text { equipment, net- } \\
\text { works... }\end{array}$ \\
\hline $\begin{array}{l}\text { Limitations : } \\
\text {-Does not address } \\
\text { the specific prob- } \\
\text { lems of software } \\
\text { maintenance } \\
\text { - Process maturity } \\
\text { of the SM is not } \\
\text { treated } \\
\text { - The process } \\
\text { improvement } \\
\text { mechanisms not } \\
\text { fully aware of } \\
\text { the practices spe- } \\
\text { cific to software } \\
\text { maintenance. }\end{array}$ & $\begin{array}{l}\text { Limitations : } \\
\text { - Specific to small } \\
\text { maintenance } \\
\text {-Major develop- } \\
\text { ments should be } \\
\text { treated as a de- } \\
\text { velopment project } \\
\text { (e.g. CMMI) }\end{array}$ & $\begin{array}{l}\text { Limitations : } \\
\text {-Does not support } \\
\text { the software main- } \\
\text { tenance }\end{array}$ \\
\hline
\end{tabular}

complex SM projects. It is noted that CMMI standard is not interested in how the TPM must be managed or the tools and practices of management. Rather, it defines the generic process to be in place to manage a project. The S3M standard treats a reduced scope of projects, namely small software maintenance. Finally, the ITIL standard is only interested in upstream operations of software 
maintenance. It puts the focus on providing support levels, and the implementation of its related processes.

Management approach based on human interaction: this is an adaptive approach with few process, practices and documentation. Also called Agile Management Approach (AM), this kind of approach is axed on people autonomy and allows an easily modifiable planning.

Born in the 21st century, the AM or lights methodologies are based on an iterative and incremental process.

With an agile approach, the software development team delivers increments, taking in account the customer feedbacks. The team learns and improves the product from iteration to another. The selection of management approach applied to the TPM is not so obvious. Before choosing one of the management approaches presented previously, it is judged to have more understanding on TPM management challenges and issues known and analyze the coverage level of these issues by each approach.

\subsection{Issues and Challenges of TPM management}

In his book on effective project management[16], Wysocki and Robert K reported that the project manager has to deal with the environment specificities of contemporary project. By quoting some of these specificities, we can realize there after the required skills of the project manager as well as the selection criteria of the effective management methodology.

First specificity is the high speed imposed by the market. The "faster products and services get to market the greater will be the resulting value to the business". The active listening to the market let to identify opportunities and quickly convert them into actions. Any delay could be exploited by the competitor. For this purpose:

- Project Manager (PM) must know how and when to introduce multiple delivery strategies and to be able to compress project schedules while fulfilling the requirements (to focus on the activities with added-value),

- The adopted management approach (MA) must exclude as possible the effort without added-value and support compressed and tight schedules.

A second feature that can be cited is the frequent change of the environment. The customer often changes what he thinks and what he wants because of the dynamic environment that surrounds him. In view of this:

- The PM should be courageous, creative and flexible to accept changes,

- The MA adopted must recognize the reality of the frequent changes of the project environment, adapt to and manage flexibly.

Another main specificity that may be mentioned is the requirement to reduce costs. This is by reducing management layers and promotion of intelligent work (work smarter, not harder). With this intention:

- The PM should establish a first level of filtering and interpreting information which enables him to ensure an intelligent communication to project stakeholders, mainly his team,

-On the other hand, the adopted approach must be well-appointed with intelligent techniques and tools, making it possible to reduce the overload of the teams.

The level of complexity of the projects that becomes more important and which increases the level of uncertainty, the adaptability and flexibility with the new business models (ex on the Internet) as many other characteristics make that in such uncertain environments, the adoption of a rigid traditional management with its multiple constraints usually generates risks to the service provider company (maintainer) and the customer.

The article reconsidered the various problems arising from SM presented by preceding research which impacts also the complicated context of the TPM. The result of this study identifies seven types of management problems, we quote:

- The programmer availability: it is related to the lack of programmers maintainers profiles and the low turnover on such profiles.

-Programmer Efficiency: skills, productivity, programmer motivation and sense of commitment are all important factors affecting the management of the software maintenance.

-Work environment: it concerns, problems related to compliance of hardware and software, system failure, data integrity and availability of the documentation.

-Customer knowledge: it is about the problems of user's expectations, lack of user training and the level of user understanding.

-Product quality: it is the quality of the original system. It includes: the quality of the design specifications and coding and the degree of compliance with the standards.

- Software and hardware limitations: mainly, it concerns the limitations in terms of resources (budget, technology...).

—Lack of user interest and lack of management support.

According to a more recent study carried out by [14]on a TPM project, it classifies problems and challenges of TPM in three areas: product, process and people.

Table 3. problems and challenges of the TPM, summarized from [14]

\begin{tabular}{ll}
\hline Problems and challenges \\
\hline Product & The requirements misunderstanding leads to poor prod- \\
& uct quality, The incompleteness qualification tests and \\
& wrong definition of priorities, The issues around the \\
& product: bugs, infrastructure problems.
\end{tabular}

Process The lack of visibility on the offshore work, Milestones unfulfilled due to bad estimates, No process applied or misapplication of the process.

People No identification with the project, Limited knowledge of testing, Problems with people: frequent changes.

To come up to this matter, the authors of [14] proposed for their case study (as an example) to implement solutions at:

-Build management: it is to set an advanced management of product construction and implement the continuous integration process.

-Communication: it's to apply strengthen communication mechanisms and communication channels. Specifically, encourage informal communication via chat and net meetings, close teams and schedule meetings between teams.

-Collaboration process: in an offshore organization, institution of a collaborative process is essential to support cooperation by reducing the effort required for communication

-Project management: it must rely on the tools and techniques of management and effective monitoring. 
-Requirements management: it concerns the definition of clear unambiguous requirements. This minimizes the risk of misunderstanding of customer needs.

- Test strategy: test coverage of all products, test automation and monitoring of coverage rate are best practices to implement to ensure product quality.

\section{CONCLUSION AND FURTHER RESEARCH}

This paper presents an insight of software maintenance, and software maintenance management related issues in outsourcing context. The manager of the TPM is confronted daily with change requests management in a very short time and with limited resources, priority management, production management and outsourcing specificities management. We observe also that the three management approaches can't cover completely TPM needs. They must be adapted to this engineering field.

This set of constraints motivates us to further dig into the most concerned management areas which is planning release management, analyze the situation and propose TPM applicable solutions to assist the manager to easily produce intelligent schedules in line with expectations and not sensitive to priorities changes.

\section{REFERENCES}

[1] Alain Abran and Hong Nguyenkim. Measurement of the maintenance process from a demand-based perspective. Journal of Software Maintenance: Research and Practice, 1993.

[2] A. April, A. Abran, and R. Dumke. Software maintenance productivity measurement. In Proceedings of the International Workshop on Software Metrics and DASMA Software Metrik congress, 2004.

[3] M.D. Aundhe and S.K. Mathew. Risks in offshore it outsourcing: A service provider perspective. European Management Journal, pages 418-428, 2009.

[4] P. Bourque and R. Dupuis. Guide to the software engineering body of knowledge 2004 version. software engineering body of knowledge, 2004.

[5] Canfora and Cimitile. Software maintenance. Artigo publicado na Univesidade de Sannio, Roma-It-lia, 2000.

[6] S. Deshpande, S. Beecham, and I. Richardson. Global software development-coordination and project management strategies from a vendor perspective. Technical report, 2011.

[7] S. Dunn. Maintenance outsourcing-critical issues. Pricewaterhouse Coopers, 2002.

[8] Galaup and Nurcan. Evolution de la maturit- du processus de maintenance du logiciel dans une organisationen mode projet. Universit- Paris1 Panth-on-Sorbonne, Institut d'administration des entreprise de Paris, 2009.

[9] P. Grubb and Takang A. A. Software maintenance: concepts and practice. World Scientific Pub Co Inc, 2003.

[10] C. Jones. Conflict and litigation between software clients and developers. IEEE Engineering Management Review 26, pages 46-54, 2001.

[11] Kitchenham, B.A., G.H. Travassos, A. von Mayrhauser, F. Niessink, N.F. Schneidewind, J. Singer, S. Takada, R. Vehvilainen, and H. Yang. Towards an ontology of software maintenance. Journal of Software Maintenance, pages 365$390,1999$.
[12] C.E. Partielle and A. Sellami. Analyse comparative des modles de maintenance du logiciel entre swebok, iso/iec 14764 et la litt-rature. Universit- d Qu-bec - Montr-al, 2000.

[13] V. M. Rota. Gestion de projet. Eyrolles, 2009.

[14] C. Seybold and R.K. Keller. Aligning software maintenance to the offshore reality. Software Maintenance and Reengineering, . CSMR 2008. 12th European Conference, pages 33-42, 2008.

[15] I Sommerville. Software engineering. McGraw -Hill, 1996.

[16] Robert K Wysocki. Effective Project Management Traditional, Agile, Extreme. Wiley, 2009. 